\title{
Coproantígenos de Fasciola hepatica de posible utilidad en el diagnóstico de la fascioliasis
}

\author{
Ana M. Espino, ${ }^{1}$ Amarilys Borges ${ }^{2}$ y Blanca E. Duménigo ${ }^{1}$
}

RESUMEN En el presente estudio se describen cuáles son los antígenos de Fasciola hepatica que están presentes en las heces de pacientes con fascioliasis crónica y de ratas infectadas experimentalmente con metacercarias de F. hepatica. Mediante el empleo de la técnica de inmunoelectrotransferencia (Western blot) con un suero hiperinmune obtenido frente a antígenos de excreción/secreción de adultos de $\mathrm{F}$. hepatica, se pudo demostrar que en las heces de los pacientes se encuentran antígenos de posible interés para el diagnóstico con masas moleculares de 14, 19, 20, 23, $25,32,46,51$ y 62 kilodaltons $(k D a)$. Además, se comprobó que algunos de estos péptidos (los de 14, 20, 23 y $51 \mathrm{kDa}$ ) son reconocidos también por la mayoría de los sueros de pacientes crónicos. Después de purificar por cromatografía de afinidad los antígenos presentes en heces de ratas con 6 a 12 semanas de infección, empleando para ello el anticuerpo monoclonal ES78 acoplado a Sepharosa $4 B-C N B r$, se identificaron seis polipéptidos de 11,14, 26, 32, 47 y $51 \mathrm{kDa}$; otros tres polipéptidos, de 17, 24 y $66 \mathrm{kDa}$, solo se pudieron identificar en heces de ratas con 10 a 12 semanas de infección. Nuestros resultados sugieren que estos polipéptidos pueden ser antígenos comunes a ambos estadios parasitarios y constituir importantes marcadores de la fascioliasis aguda y crónica, en particular los de 14, 24, 26 y $51 \mathrm{kDa}$, puesto que reaccionaron con el inmunosuero, los sueros humanos y el anticuerpo monoclonal ES78.

La fascioliasis es una enfermedad parasitaria producida por tremátodos del género Fasciola. La especie más común, Fasciola hepatica, es un parásito digenético y hermafrodita que se localiza en los conductos biliares de mamí-

\footnotetext{
1 Departamento de Parasitología, Instituto de Medicina Tropical "Pedro Kourí", Ciudad Habana, Cuba. Toda la correspondencia debe ser enviada a Ana M. Espino a la siguiente dirección postal: Instituto de Medicina Tropical "Pedro Kourí", Apartado 601, Zona 13, Ciudad Habana, Cuba. Fax: (53-7) 246051. Correo electrónico: amespino@ ipk.sld.cu

2 Centro Provincial de Perfeccionamiento Médico "Simón Bolivar", Pinar del Río, Cuba.
}

feros herbívoros y del hombre. Su distribución es cosmopolita y se encuentra fundamentalmente en regiones dedicadas a la cría de ganado ovino y bovino donde, además, existen moluscos de diversos géneros y especies que le sirven de hospederos intermediarios. En Cuba la fascioliasis es considerada una de las enfermedades zoonóticas de mayor importancia médico-veterinaria debido a las cuantiosas pérdidas que ocasiona a la industria pecuaria y alimentaria (1), a la presencia cada vez más frecuente de brotes epidémicos (2) y al número creciente de casos esporá- dicos que anualmente se detectan en nuestras instituciones hospitalarias.

Hasta el momento, el diagnóstico de la fascioliasis se ha basado en la identificación de los huevos del parásito en las heces o en el líquido duodenal del individuo parasitado. Sin embargo, este diagnóstico carece de sensibilidad en la fase prepatente de la infección, debido a que el parásito se encuentra en forma inmadura. En etapas posteriores, cuando el parásito ha llegado a la madurez sexual e inicia la oviposición, el diagnóstico también se ve dificultado por la intermitencia en la ex- 
creción de huevos, que hace necesaria la realización de exámenes parasitológicos seriados. Recientemente, nuestro laboratorio desarrolló un ensayo inmunoenzimático de tipo ELISA con doble anticuerpo (ELISA sandwich) basado en la detección de antígenos de F. hepatica en heces de pacientes infectados (3) que utiliza el anticuerpo monoclonal (AcMo) ES78 para la captura específica de los antígenos (4). Este procedimiento ha demostrado ser altamente sensible y específico y permite la detección de la infección activa por $F$. hepatica tanto en la fase prepatente como en la fase patente de la infección $(3,5)$.

Un estudio reciente de caracterización del epitopo antigénico reconocido por el anticuerpo monoclonal ES78 realizado en nuestro laboratorio, demostró que este anticuerpo reconoce una estructura proteica en la que intervienen uno o más enlaces disulfuro que mantienen la conformación tridimensional. Esta estructura proteica se encuentra unida a un "núcleo" disacárido formado por galactosa- $\beta(1-3)-\mathrm{N}$ acetilgalactosamina, unido a su vez a los aminoácidos serina o treonina por un enlace covalente en el que interviene una molécula de oxígeno (6). Este determinante antigénico está presente en un grupo de antígenos de excreción/secreción (ES) de adultos de F. hepatica con masas moleculares relativas (Mr) de 6,5, 10, 11, 17 y 23-27 kilodaltons $(\mathrm{kDa})(6,7)$, y es muy probable que estos polipéptidos, o al menos algunos de ellos, estén presentes en las heces de individuos con infección activa y que se encuentren indistintamente en las fases prepatente y patente de la infección. En el presente trabajo nos propusimos: 1) identificar por inmunoelectrotransferencia (Western blot) cuáles son los antígenos de ES de $F$. hepatica que están presentes en las heces de pacientes con infección crónica, empleando para ello un suero hiperinmune frente a antígenos de ES y sueros de pacientes, y 2) determinar qué antígenos son reconocidos por el AcMo ES78 durante las fases prepatente y patente de la infección y estimar cuáles de estos antígenos podrían ser comunes a los estadios inmaduros y maduros del parásito.

\section{MATERIALES Y MÉTODOS}

\section{Antígenos de F. hepatica}

Los antígenos ES de F. hepatica se obtuvieron mediante la técnica de mantenimiento in vitro, estandarizada previamente hasta lograr la supervivencia de $100 \%$ de los parásitos (8). El procedimiento fue el siguiente: se extrajeron adultos de $F$. hepatica de los conductos biliares de reses infectadas y sacrificadas en mataderos locales; una vez extraídos, los parásitos se lavaron repetidamente con solución salina tamponada con fosfato (PBS) 0,05 M (pH 7,2), con el propósito de eliminar todos los restos de sangre y bilis, y se incubaron individualmente en frascos de cultivo con 5 $\mathrm{ml}$ de medio RPMI-1640 (Sigma Chemical Co., St. Louis, Missouri, Estados Unidos de América) suplementado con L-glutamina ( $\mathrm{pH} \mathrm{7,2);} \mathrm{después} \mathrm{de} 24$ horas de incubación se recogieron los medios de cada frasco, se mezclaron e inmediatamente se les añadió una mezcla de inhibidores de proteasas compuesta por iodoacetamida, ácido etilendiaminotetracético (EDTA, Sigma Chemical Co.) y fenilmetilsulfonilfluoruro (PMSF, Sigma Chemical Co.) a una concentración final de $2 \mathrm{mM}, 5 \mathrm{mM}$ y 8 $\mathrm{mM}$, respectivamente; posteriormente, se centrifugó a $3000 \mathrm{~g}$ a $4{ }^{\circ} \mathrm{C}$ durante 10 minutos y se recogió el sobrenadante que contenía los productos de ES de los parásitos, se concentró por ultrafiltración empleando una membrana YM-10 (masa molecular > 10000 ; Amicon, Lexington, Massachusetts, Estados Unidos de América) y, finalmente, se dializó con una columna de Sephadex G-25 (PD-10; Amersham-Pharmacia, Uppsala, Suecia). Los antígenos así obtenidos se conservaron a $-20^{\circ} \mathrm{C}$ en alícuotas de $1 \mathrm{ml}$ hasta su uso.

\section{Anticuerpo monoclonal}

El AcMo utilizado en este trabajo (ES78, subclase $\operatorname{IgG}_{2 \mathrm{a}}$ ) (4), dirigido frente a antígenos ES de adultos de $F$. hepatica, fue donado por el laboratorio de hibridomas del Departamento de Parasitología del Instituto de Medicina Tropical "Pedro Kourí" en forma de lí- quido ascítico, por lo que, para su uso, se purificó por cromatografía de afinidad con una columna de proteína ASepharosa en un equipo de alta resolución (FPLC, Amersham-Pharmacia) y se concentró por ultrafiltración con una membrana YM-100 (Amicon) hasta alcanzar una concentración de $2 \mathrm{mg} / \mathrm{mL}$, que fue determinada por el método del ácido bicinconínico (9); posteriormente se dializó frente a un tampón de bicarbonato de sodio 0,1 M (pH 8,5) mediante columnas de Sephadex G-25 (PD-10, Amersham-Pharmacia).

\section{Obtención de suero hiperinmune}

Se inmunizaron conejos con antígenos ES de F. hepatica mediante inyecciones subcutáneas de $500 \mu \mathrm{g}$ de los antígenos emulsionados en adyuvante completo de Freund en la primera dosis, y en adyuvante incompleto en las tres restantes, que se administraron a intervalos de 15 días. Se obtuvo sangre de los animales antes del inicio del protocolo de inmunización y al final del mismo. Mediante ELISA indirecto con antígenos de ES a la dilución de 1:400, se comprobó que los sueros de los conejos obtenidos antes de la inmunización no reaccionaban con los antígenos de ES (densidad óptica media: $\left.\mathrm{DO}_{\text {media }}=0,05 \pm 0,04\right)$, mientras que al finalizar el protocolo de inmunización los valores fueron muy elevados $\left(\mathrm{DO}_{\text {media }}=1,98 \pm 0,08\right)$. Al evaluar el inmunosuero a diluciones desde 1:400 a 1:102 000 se obtuvo un título de anticuerpos de 1:51000, considerándose como título de anticuerpos aquella dilución cuyo valor de DO duplicó el valor del suero negativo.

\section{Obtención y procesamiento de sueros y muestras fecales humanas}

Se estudiaron 10 pacientes con fascioliasis cuyo diagnóstico fue confirmado mediante el hallazgo de huevos en heces y que no habían recibido tratamiento fasciolicida durante los tres meses que antecedieron al estudio. Estos pacientes presentaban elevados niveles de anticuerpos frente a antígenos 
de ES de F. hepatica (títulos > 1:25 000) medidos por la técnica de ELISA según el procedimiento descrito en trabajos previos (10) y elevados niveles de coproantígenos $(\mathrm{DO}>1,0)$ medidos por la técnica de ELISA sandwich con el AcMo ES78 (3). De cada paciente, se obtuvo una muestra de $5 \mathrm{~mL}$ de sangre y abundante materia fecal, que se emulsionó en solución salina al 0,9\% y se dejó reposar durante 4 horas a temperatura ambiente, alternando el reposo con agitación vigorosa cada 30 minutos. Posteriormente, cada emulsión se mantuvo en reposo toda la noche a $4{ }^{\circ} \mathrm{C}$ y a continuación se centrifugó a $250 \mathrm{~g}$ durante 15 minutos para eliminar el material insoluble y se volvió a centrifugar a $10000 \mathrm{~g}$ durante 1 hora a $4{ }^{\circ} \mathrm{C}$ para aclarar el sobrenadante de cada emulsión. El sobrenadante obtenido se sometió a una doble precipitación al 50\% con solución saturada de sulfato de amonio y posteriormente se centrifugó a $500 \mathrm{~g}$ durante 20 minutos a $4{ }^{\circ} \mathrm{C}$. El precipitado obtenido se disolvió y dializó de forma exhaustiva frente a PBS con una columna de Sephadex G-25, se pasó por un filtro de $0,45 \mu \mathrm{m}$ y se concentró por ultrafiltración con membrana YM-10 (masa molecular $>10000$ ) hasta un volumen equivalente al de la emulsión inicial de cada paciente. A cada sobrenadante fecal se le añadió una mezcla de inhibidores de proteasas compuesta por iodoacetamida, EDTA y PMSF a una concentración final de 2, 5 y 8 mM, respectivamente, y finalmente se conservó a $-20^{\circ} \mathrm{C}$ en alícuotas de $1 \mathrm{~mL}$ hasta su estudio por inmunoelectrotransferencia.

\section{Electroforesis en gel de poliacrilamida-dodecilsulfato sódico (SDS-PAGE)}

La separación de los sobrenadantes en sus diferentes componentes se realizó mediante electroforesis en condiciones reductoras, con gel de poliacrilamida, siguiendo el método descrito por Laemmli (11). Se emplearon geles de separación al $12 \%$ de acrilamida (concentración total del monómero, acrilamida: $\mathrm{T}=30 \%$; concentración del agente entrecruzador, bisacrilamida:
$\mathrm{C}=2,6 \%$ ). El antígeno ES y los 10 sobrenadantes fecales se diluyeron a razón de 2:1 en el tampón de muestras y se desnaturalizaron a $100{ }^{\circ} \mathrm{C}$ durante 3 minutos, aplicando un volumen máximo de $20 \mu \mathrm{L}$ de cada muestra. La separación electroforética se realizó a un voltaje constante de $200 \mathrm{~V}$.

\section{Inmunoelectrotransferencia}

Una vez separados los antígenos y los sobrenadantes fecales por SDS-PAGE, se transfirieron a membranas de nitrocelulosa con poros de $0,2 \mu \mathrm{m}$ de diámetro. Las membranas se analizaron siguiendo el método de Tsang et al. (12), que consiste en bloquear la nitrocelulosa con una solución compuesta por leche descremada al 2,5\% disuelta en PBST (PBS con $0,05 \%$ de Tween 20). A continuación las membranas se sumergieron en una dilución 1:100 de suero hiperinmune en PBST durante 16 horas a $4{ }^{\circ} \mathrm{C}$. Después de tres lavados de $5 \mathrm{mi}$ nutos, la nitrocelulosa se incubó en solución de inmunoconjugado (anti-IgG de conejo-peroxidasa, 1:1000) durante dos horas a temperatura ambiente y a continuación se lavó tres veces. Finalmente, se añadió el sustrato $(4 \mathrm{mg}$ de diaminobenzidina $+10 \mathrm{~mL}$ de citratofosfato $0,1 \mathrm{M}(\mathrm{pH} 5,0)+10 \mu \mathrm{lde} \mathrm{H}_{2} \mathrm{O}_{2}$ al $30 \%$ peso/volumen), y cuando las bandas se hicieron visibles se detuvo la reacción eliminando la solución de sustrato y sumergiendo la nitrocelulosa en agua destilada. Como control negativo se utilizó suero de conejo sin inmunizar.

Una vez que los 10 sobrenadantes fecales se enfrentaron al suero hiperinmune, se repitió el estudio, pero sustituyendo el suero hiperinmune por sueros de pacientes diluidos a 1:100, y empleando anti-IgG humana conjugada con peroxidasa (Sigma Chemical Co.) diluida a 1:2 000 en PBST con 10\% de suero de ternera. En este caso se utilizó como control negativo un suero de persona sana.

\section{Infección experimental}

Por vía oral, se infectaron 10 ratas Wistar de $160 \mathrm{~g}$ de peso con 25 meta- cercarias de F. hepatica. Se recogieron todas las excretas de estos animales a las $2,4,6,8,10$ y 12 semanas de la infección, se mezclaron y se procesaron del mismo modo que las muestras fecales humanas. Cada mezcla de sobrenadantes fue examinada por ELISA sandwich con el AcMo ES78 para determinar los niveles de coproantígenos presentes en cada semana de infección. Además, cada muestra fecal se estudió al microscopio por la técnica de sedimentación simple con el propósito de determinar el inicio de la fase patente.

\section{Purificación de los antígenos presentes en las muestras fecales de las ratas infectadas}

La purificación de los antígenos presentes en las muestras fecales de las ratas infectadas experimentalmente se realizó mediante cromatografía de afinidad. Se acoplaron $21 \mathrm{mg}$ del AcMo ES78 a 2 g de Sepharosa-4B activada con CNBr (Amersham-Pharmacia) en $20 \mathrm{~mL}$ de tampón de acoplamiento $\mathrm{NaHCO}_{3} 0,1 \mathrm{M}-\mathrm{NaCl} 0,5 \mathrm{M}(\mathrm{pH} 8,5)$ siguiendo las recomendaciones del fabricante. El exceso de grupos activos se bloqueó por incubación a $4{ }^{\circ} \mathrm{C}$ con $40 \mathrm{~mL}$ de glicina 0,1 M disuelta en tampón de acoplamiento. El gel fue transferido a una columna de C10/10 (Amersham-Pharmacia) y lavado de forma alterna con tampón de acoplamiento y tampón de acetato $0,1 \mathrm{M}(\mathrm{pH}$ $4,0)$ con $0,5 \mathrm{M}$ de $\mathrm{NaCl}$. Los sobrenadantes fecales correspondientes a las semanas 6 a 12 se aplicaron de forma individual a la columna, y los antígenos que no quedaron retenidos se eluyeron con PBS a una velocidad de flujo lineal de $8,9 \mathrm{~mL} / \mathrm{cm}^{2} / \mathrm{h}$. Los antígenos retenidos se eluyeron a esa misma velocidad de flujo empleando una solución de $\mathrm{KCl} 1 \mathrm{M}$ (pH 3,0), y posteriormente se neutralizaron con la adición de varias gotas de Tris $2 \mathrm{M}$ ( $\mathrm{pH} \mathrm{10)}$. Después de recoger cada una de las fracciones aisladas en cada semana de infección, se dializó frente a PBS y se concentró por ultrafiltración hasta un volumen de $100 \mu \mathrm{L}$. Finalmente cada fracción se secó al vacío y se reconsti- 
CUADRO 1. Polipéptidos identificados en muestras fecales humanas mediante inmunoelectrotransferencia (Western blot) con suero hiperinmune de conejo y sueros humanos con relación a los purificados en las heces de ratas infectadas experimentalmente mediante cromatografía de afinidad con el AcMo ES78

\begin{tabular}{|c|c|c|c|}
\hline \multirow{2}{*}{$\begin{array}{l}\text { Polipéptido } \\
\text { (kDa) }\end{array}$} & \multicolumn{2}{|c|}{ Muestras fecales positivas (\%) } & \multirow{2}{*}{$\begin{array}{c}\text { Semanas de infección } \\
\text { en que fue aislado con ES78 } \\
\text { de la heces de ratas }\end{array}$} \\
\hline & Inmunosuero de conejo & Sueros humanos & \\
\hline 62 & 40 & 80 & $66 \mathrm{kDa}^{\mathrm{a}}$ semanas $10-12$ \\
\hline 51 & 80 & 80 & Semanas 6-12 \\
\hline 46 & 70 & 30 & $47 \mathrm{kDa}^{\mathrm{a}}$ semanas $6-12$ \\
\hline 43 & 50 & 70 & No \\
\hline 41 & 70 & 70 & No \\
\hline 38 & 70 & 40 & No \\
\hline 32 & 70 & 30 & Semanas 6-12 \\
\hline 30 & 60 & 60 & No \\
\hline 27 & 60 & 90 & $26 \mathrm{kDa}^{\mathrm{a}}$ semanas $6-12$ \\
\hline 25 & 100 & 20 & No \\
\hline 23 & 80 & 70 & $24 \mathrm{kDa}$ semanas $10-12$ \\
\hline 20 & 80 & 80 & No \\
\hline 19 & 80 & 30 & $17 \mathrm{kDa}^{\mathrm{a}}$ semanas $10-12$ \\
\hline 14 & 70 & 90 & Semanas 6-12 \\
\hline 11 & 80 & 40 & Semanas 6-12 \\
\hline
\end{tabular}

a Polipéptido de masa molecular semejante al identificado por inmunoelectrotransferencia (Western blot).

tuyó en $20 \mu \mathrm{L}$ del tampón de aplicación para ser estudiada por SDSPAGE. Al finalizar la electroforesis, el gel se tiñó con nitrato de plata (Silver Stain Plus, Bio-Rad Laboratories, Inc., Hercules, California, Estados Unidos de América), procediéndose posteriormente al cálculo de la masa molecular de cada uno de los componentes identificados en cada semana de infección.

\section{RESULTADOS}

\section{Resultados obtenidos} por inmunoelectrotransferencia al enfrentar las muestras fecales humanas contra el suero hiperinmune y los sueros de pacientes

Cuando se estudiaron los 10 sobrenadantes fecales con el suero hiperinmune mediante inmunoelectrotransferencia, se observaron 15 componentes polipeptídicos de 11 a $62 \mathrm{kDa}$, once de los cuales (de 11, 14, 19, 20, 23, 25, 32, $38,41,46$ y $51 \mathrm{kDa}$ ) se identificaron en más de $60 \%$ de los sobrenadantes fecales.

$\mathrm{Al}$ enfrentar los sobrenadantes fecales a los sueros de los pacientes se identificaron los mismos 15 polipéptidos que con el inmunosuero, de los cuales solo 8 (de 14, 20, 23, 27, 41, 43, 51 y $62 \mathrm{kDa}$ ) fueron reconocidos por más de $60 \%$ de los sueros humanos, y de este grupo solo los de 14, 20, 23, 41 y 51 kDa cumplían la doble condición de ser reconocidos por el inmunosuero en más de $60 \%$ de los sobrenadantes fecales y a la vez ser reconocidos por más de $60 \%$ de los sueros humanos (cuadro $1 \mathrm{y}$ figura 1 ).

\section{Resultados de la infección experimental}

Los primeros huevos de F. hepatica aparecieron a las seis semanas de la infección en uno de los animales y a las ocho semanas en otros dos; a partir de las diez semanas todos los animales infectados eliminaban huevos (figura 2).

Después de analizar los sobrenadantes fecales de ratas con la prueba de ELISA sandwich con AcMo ES78 se encontró reacción positiva a partir de la cuarta semana de infección $\left(\mathrm{DO}_{\text {media }}=\right.$ $0,64)$, que se incrementó de forma paulatina hasta alcanzar el valor máximo a las diez semanas $\left(\mathrm{DO}_{\text {media }}=1,5\right)$.

\section{Purificación de coproantígenos por cromatografía de afinidad}

Cuando los antígenos eluidos de la columna de afinidad en cada una de las semanas posteriores a la infección fueron estudiados por SDS-PAGE, se observaron seis polipéptidos de 11, 14, $26,32,47$ y $51 \mathrm{kDa}$ que se encontraban presentes desde la sexta semana de infección. Otros tres componentes $(17,24$ y $66 \mathrm{kDa}$ ) solo se identificaron a partir de la décima semana de infección (cuadro 1). Los componentes purificados en la cuarta semana no se pudieron identificar debido a que presentaban una concentración de proteínas muy baja.

\section{DISCUSIÓN}

La identificación y aislamiento de antígenos de parásitos es de fundamental importancia, pues con ello no solo se logra una mejor comprensión de los mecanismos de la inmunidad, sino que también se facilita la prepara-

FIGURA 1. Inmunoelectrotransferencia (Western blot) de los sobrenadantes fecales contra sueros humanos.

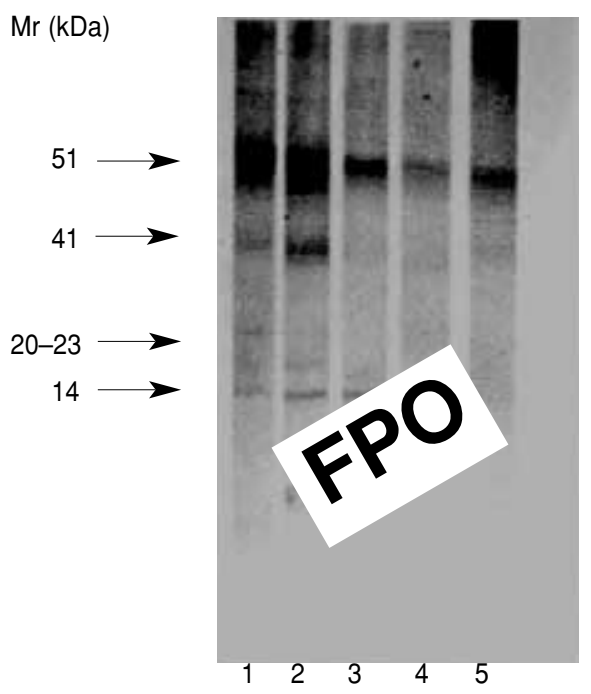

Las flechas señalan los componentes antigénicos mayoritarios reconocidos en más de $60 \%$ de las heces estudiadas. 1 2 y 3 : pacientes en los que se identificaron los polipéptidos de $14,20-23,41$ y $51 \mathrm{kDa} .4$ y 5 : pacientes en los que los componentes de 14 y 20-23 kDa estaban ausentes. 
FIGURA 2. Dinámica de los coproantígenos y de la excreción de huevos en ratas con infección primaria por Fasciola hepatica

No. de animales DO $492 \mathrm{~nm}$ positivos a huevos

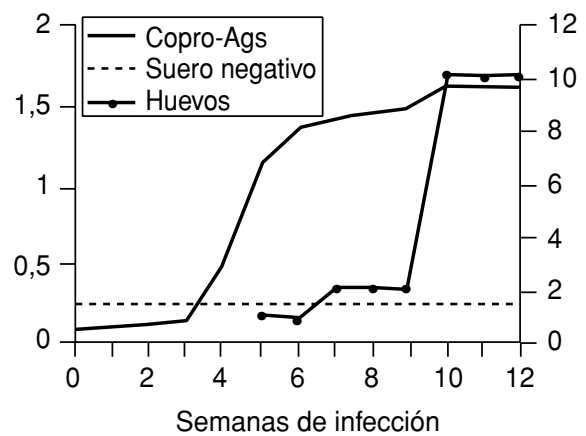

ción de antígenos purificados, útiles para el diagnóstico de las infecciones y las enfermedades parasitarias (13).

De los antígenos de F. hepatica, los llamados antígenos metabólicos o de excreción/secreción han resultado ser los más específicos para el diagnóstico serológico de la fascioliasis (10) y se plantea, además, que son los primeros antígenos del parásito en inducir la respuesta inmune (14). Estudios previos han demostrado la identidad existente entre los antígenos obtenidos in vitro y los excretados por el parásito in vivo (15). Teniendo en cuenta estos antecedentes, en el presente estudio utilizamos un suero hiperinmune específico frente a antígenos de ES de $F$. hepatica y sueros de pacientes con fascioliasis crónica para identificar cuáles son los antígenos del parásito presentes en las heces de pacientes con fascioliasis.

Como se aprecia en nuestros resultados, el inmunosuero identificó once polipéptidos de 11 a $62 \mathrm{kDa}$ en las heces de más de $60 \%$ de los pacientes con fascioliasis, y cinco de ellos reaccionaron también con la mayoría de los sueros humanos. Aunque con algunas diferencias, el perfil antigénico reconocido por el inmunosuero fue muy semejante al obtenido con los sueros humanos, lo que puede deberse a que se trata de sueros policlonales que responden a antígenos del estadio adulto del parásito. Sin embargo, los sueros humanos contienen anticuerpos que responden a una infección natural y han sido inducidos por antígenos de ES y por otros antígenos del parásito, como por ejemplo antígenos del tegumento, por lo que es posible que ciertos polipéptidos que no han sido identificados por el inmunosuero ES pudieran ser muy reactivos con los sueros humanos y viceversa, lo que explicaría las diferencias encontradas en el patrón de reconocimiento antigénico de ambos sueros.

Un hecho a destacar en este estudio es que en la producción del inmunosuero no se incluyeron procedimientos de adsorción con órganos de mamíferos para eliminar posibles reacciones cruzadas, en el supuesto caso en que los repetidos lavados realizados a los parásitos para eliminar los restos de sangre y bilis no fuesen suficientes para garantizar la especificidad de los antígenos obtenidos del cultivo. No obstante, la posibilidad de que la mayor variedad de polipéptidos encontrados con el uso del inmunosuero se debiera a reacciones cruzadas de este tipo queda descartada si se tiene en cuenta que al sustituir el inmunosuero por suero de conejo normal no se observó ninguna reacción positiva. Además, en estudios anteriores en los que los antígenos de ES han sido utilizados en pruebas de ELISA para detectar la presencia de anticuerpos en bovinos y humanos infectados con F. hepatica, se han podido diferenciar con claridad los sueros positivos de los negativos e incluso excluir significativamente las reacciones cruzadas con otros helmintos (16).

Teniendo en cuenta que el inmunosuero utilizado en este estudio fue obtenido contra antígenos del parásito en fase adulta y que los sueros procedían de pacientes con fascioliasis confirmada, se podría concluir que los polipéptidos de 14, 20, 23, 27, 41 y 51 kDa son excretados por el parásito adulto, de forma que funcionarían como marcadores de la fase patente de la infección.

El AcMo ES78 es muy específico y útil como anticuerpo de captura en una prueba de ELISA sandwich para el diagnóstico de la fascioliasis humana y animal $(2,3,7)$, ya que permite detectar la infección activa en diferentes fases de la enfermedad, sin reaccionar de forma cruzada con muestras de suero y heces de animales y pacientes con otras infecciones parasitarias. Este AcMo se obtuvo frente a antígenos de ES de adultos de F. hepatica y los estudios de caracterización realizados demostraron que reconocía un epitopo que se encuentra en varios polipéptidos de 6,5, 10, 11, 17 y 23-27 kDa. En el presente trabajo procedimos al aislamiento de los antígenos que aparecían en muestras fecales de animales infectados con F. hepatica mediante un procedimiento cromatográfico semejante al utilizado en el estudio de caracterización al que hacemos referencia. Como se muestra en nuestros resultados, se purificaron por cromatografía de afinidad nueve polipéptidos de 11, $14,17,24,26,32,47,51$ y $66 \mathrm{kDa}$, algunos de los cuales $(11,17,24$ y $26 \mathrm{kDa})$ coinciden en tamaño con los aislados a partir de los antígenos de ES.

Un resultado que hay que hacer notar es que, aunque el AcMo ES78 es específico frente a los antígenos de $F$. hepatica, reaccionó en los sobrenadantes fecales frente a un mayor número de polipéptidos que con antígenos de ES. Una posible explicación a tan variada especificidad podría radicar en las características del epitopo antigénico reconocido por este anticuerpo monoclonal, que como ya se ha citado, está compuesto por residuos glucosídicos y proteínicos que, al parecer, constituyen un "núcleo" polipeptídico central, al cual se unen de manera específica otros polipéptidos de menor tamaño durante el proceso de glucosilación (6). Teniendo en cuenta esto, parece posible que el parásito excrete in vivo un mayor número de moléculas de este tipo, lo que explicaría el hallazgo en heces de un mayor número de polipéptidos reconocidos por el AcMo ES78 que el descubierto en estudios anteriores. Hanna y Trudgett (17) enunciaron una hipótesis semejante, después de desarrollar seis anticuerpos monoclonales frente a antígenos de gránulos $\mathrm{T} 1$ del tegumento del parásito, cuya caracterización bioquímica demostró la existencia de un componente proteínico de $50 \mathrm{kDa}$ unido por puente disulfuro a otros polipépti- 
dos de 25 a 40 kDa y a galactosa, formando parte de varias cadenas de carbohidratos laterales.

De los polipéptidos aislados de las heces, al menos los de 24, 26, 32 y 51 kDa están muy cercanos o probablemente incluidos en el intervalo de masa molecular de los reconocidos por los anticuerpos monoclonales arriba mencionados. Teniendo en cuenta que el parásito adulto segrega antígenos a través de gránulos de tipo T2 y que los componentes segregados por ambos tipos de gránulos son antigénicamente similares (18), es posible que los polipéptidos identificados en el presente estudio sean antígenos liberados a través de gránulos T2 que también podrían estar presentes en los gránulos $\mathrm{T} 1$ del parásito inmaduro. Esta hipótesis se fundamenta también en el hecho de que se identificasen seis polipéptidos de 11 a 51 kDa que se encontraron de forma permanente en las heces de ratas con 6 a 12 semanas de infección.

Si analizamos de forma global los componentes antigénicos identificados en la mayoría de las heces por el inmunosuero y por los sueros de humanos en fase patente y los comparamos con los aislados de las heces de animales en fase prepatente, vemos que algunos de ellos (en especial los de 14, 23, 27 y 51 $\mathrm{kDa}$ ) fueron los que se identificaron con más frecuencia en las heces de pacientes crónicos y en las de animales en diferentes fases de la enfermedad. Teniendo en cuenta el ciclo intraorgánico del parásito dentro del huésped, donde durante las primeras 6 semanas de infección el parásito inmaduro se encuentra migrando por el parénquima hepático y no llega a adulto hasta después de 10 semanas en los conductos biliares (19), podríamos sugerir que estos polipéptidos son característicos del parásito inmaduro y que además se encuentran presentes en la forma adulta, lo que los convierte sin duda en importantes marcadores de las fases prepatente y patente de la infección.

Se ha comprobado la existencia de un polipéptido de ES de 17 kDa presente en sueros de bovinos y ovinos con ocho semanas de infección y en pacientes con infección crónica, por lo que ha sido considerado un marcador importante de la infección por F. hepatica (20). En el presente estudio se aisló un polipéptido de $17 \mathrm{kDa}$ a partir de las heces de ratas con 10 a 12 semanas de infección, aunque este polipéptido no se observó cuando las muestras fecales fueron enfrentadas a los sueros de pacientes.
Los antígenos identificados y aislados en el presente trabajo son potencialmente útiles para el diagnóstico debido a que han sido identificados por un inmunosuero obtenido frente a antígenos de ES, o aislados con un AcMo de reconocida importancia para el diagnóstico. De este modo, su utilización en ensayos de inmunoelectrotransferencia y ELISA en sustitución de extractos antigénicos no purificados podría mejorar el diagnóstico de la fascioliasis. Por otro lado, debido a que se ha demostrado la utilidad de los antígenos de ES en la inducción de protección frente a la infección por F. hepatica $(21,22)$, en la que los anticuerpos podrían jugar un papel destacado en la inmunidad, creemos que algunos de los antígenos identificados en este trabajo podrían ser importantes en la inducción de los mecanismos inmunes de protección. Tenemos proyectados nuevos estudios en los que se obtendrán antígenos de ES de parásitos inmaduros de F. hepatica, a partir de los cuales se podrán aislar los antígenos identificados por el AcMo ES78, con objeto de compararlos con antígenos ES de parásitos adultos y con los obtenidos en el presente estudio a partir de muestras fecales, para el diagnóstico y la inmunoprofilaxis de la fascioliasis.

\section{REFERENCIAS}

1. Cuba, Ministerio de Salud Pública 1991/1995. Cuadro Epidemiológico Nacional, 1995. Ciudad de La Habana: Ministerio de Salud Pública; 1995.

2. Espino AM, Díaz A, Pérez A, Finlay CM. Dynamics of antigenemia and coproantigens during a human Fasciola hepatica outbreak. J Clin Microbiol 1998;36:2723-2727.

3. Espino AM, Finlay CM. Sandwich enzymelinked immunosorbent assay for detection of excretory secretory antigens in humans with fascioliasis. J Clin Microbiol 1994;32:190-193.

4. Espino AM, Marcet R, Finaly CM. Detection of circulating excretory secretory antigens in human fascioliasis by sandwich enzymelinked immunosorbent assay. J Clin Microbiol 1990;28:2637-2640.

5. Espino AM, Marcet R, Finlay CM. Fasciola hepatica: detection of antigenemia and coproantigens in experimentally infected rats. Exp Parasitol 1997;85:117-120.
6. Díaz A, Espino AM, Marcet R, Otero O, Torres $D$, Finlay $C M$, et al. Partial characterization of the epitope on excretory-secretory products of Fasciola hepatica recognized by monoclonal antibody ES78. J Parasitol 1998;84:55-61.

7. Duménigo BE, Espino AM, Finlay CM. Detection of Fasciola hepatica antigen in cattle faeces by a monoclonal antibody-based sandwich immunoassay. Res Vet Sci 1996;60: 278-279.

8. Espino AM, Duménigo BE, Huesca N, Finlay CM. Mantenimiento in vitro de adultos de Fasciola hepatica. Obtención de antígenos de excreción secreción. Rev Salud Animal 1988;10: 287-293.

9. Smith PK, Krohn RI, Hermanson GT, Mallia AK, Gartner FH, Provenzano MD, et al. Measurement of protein using bicinchoninic acid. Anal Biochem 1985;150:76-85.

10. Espino AM, Duménigo BE, Fernández R, Finlay CM. Immunodiagnosis of human fascio- liasis by enzyme-linked immunosorbent assay using excretory-secretory products. Am J Trop Med Hyg 1987;37:605-608.

11. Laemmli UK. Cleavage of structural proteins during the assembly of the head of bacteriophage T4. Nature 1970;227:680-685.

12. Tsang VCW, Peralta JM, Simons AR. Enzyme-linked immunoelectrotransfer blot technique (EITB) for studying the specificities of antigens and antibodies separated by gel electrophoresis. Methods Enzymol 1983;92: 377-391.

13. Santiago de Weil N, Hillyer GV, Garcia-Rosa $\mathrm{M}$, Morales MH. Identification of functional Fasciola hepatica antigens in experimental infections in rabbits. Am J Trop Med Hyg 1986; 35:135-140.

14. Sandeman RM, Howell MJ. Precipitating antibodies against excretory-secretory antigens of Fasciola hepatica in sheep serum. Vet Parasitol 1981;9:35-46. 
15. Lehner RP, Sewel MMH. A study of the antigens produced by adult Fasciola hepatica maintained in vitro. Parasite Immunol 1980;2:99-109.

16. Hernández HM, Duménigo BE, Espino AM, Marcet R, Finlay CM. Serodiagnóstico de la fascioliasis bovina. Rev Cub Cienc Vet 1999; 25:15-17.

17. Hanna REB, Trudget AG. Fasciola hepatica: development of monoclonal antibodies and their use to characterize a glycocalyx antigen in migrating flukes. Parasite Immunol 1983;5: $409-425$.

18. Hanna REB. Fasciola hepatica: glycocalyx replacement in the juvenile as a possible mech- anism of protection against host immunity. Exp Parasitol 1980;50:103-114.

19. Chen MG, Mott KE. Progress in assessment of morbidity due to Fasciola hepatica infection. A review of a recent literature. Trop Dis Bull 1990;87:1-38.

20. Hillyer GV, Soler de Galanes M. Identification of a 17-kilodalton Fasciola hepatica immunodiagnostic antigen by the enzyme-linked immunoelectrotransfer blot technique. J Clin Microbiol 1988:26:2048-2053.

21. Haroun EM, Hammond JE, Sewel MMH. Resistance to Fasciola hepatica in rats and rabbits following implantation of adult flukes contained in diffusion chambers. Res Vet Sci 1980;29:310-314

22. Lang BZ, Hall RF. Host-parasite relationships of Fasciola hepatica in the white mouse. VIII. Successful vaccination with culture incubate antigens and antigens from sonic disruption of immature worms. J Parasitol 1977;63:1046-1049.

Manuscrito recibido el 1 de diciembre de 1998 y aceptado para publicación, tras revisión, el 22 de marzo de 2000.

ABSTRACT
Identification and isolation
of coproantigens of
Fasciola hepatica that are
potentially useful in the
diagnosis of fascioliasis

ABSTRACT

This study describes which antigens of Fasciola hepatica are present in the feces of patients with chronic fascioliasis and in the feces of rats infected experimentally with $F$. hepatica metacercariae. Using a Western blot assay technique with hyperimmune serum obtained from excretory-secretory antigens of adult F. hepatica, we found in the patients' feces antigens of possible diagnostic interest, with molecular weights of 14 $19,20,23,25,32,46,51$, and 62 kilodaltons (kDa). In addition, we showed that the peptides of $14,20,23$, and $51 \mathrm{kDa}$ are also recognized by the majority of the sera from chronic patients. We used affinity chromatography to purify the antigens present in the feces of rats that had been infected for 6 to 12 weeks, using ES78 monoclonal antibody bound to $\mathrm{CNBr}$-activated Sepharose $4 \mathrm{~B}$. Through that approach, we identified six polypeptides, of $11,14,26,32,47$, and $51 \mathrm{kDa}$; three more polypeptides, of 17,24 , and $66 \mathrm{kDa}$, could only be identified in the feces of rats that had been infected for 10 to 12 weeks. Our results suggest that these polypeptides could be antigens common to both parasitic stages. This is particularly true for the polypeptides of 14, 24, 26, and $51 \mathrm{kDa}$, because they reacted with the immune sera, the human sera, and the ES78 monoclonal antibody. These polypeptides could be important markers for acute and chronic fascioliasis. 